\title{
Audit on epilepsy among patients attending a Neurology Clinic
}

\author{
KP Karunatilake', KD Pathirana ${ }^{2}$, DI Kariyawasam ${ }^{3}$, T Welgamage ${ }^{3}$, PLAN Liyanage ${ }^{3}$ \\ ${ }^{1}$ Registrar in Medicine, ${ }^{2}$ Consultant Neurologist, Professorial Medical Unit, Karapitiya Teaching \\ Hospital, Galle. \\ ${ }^{3}$ Research Assistant, Department of Medicine, Faculty of Medicine, University of Ruhuna, Galle.
}

\section{Introduction}

Epilepsy is one of the common chronic conditions seen in Neurology Clinics. The patients with epilepsy need not only medication but health education and social support as well. Audit on treatment is important to compare the management with the accepted practice, identify deficiencies and make suggestions for improvements.

\section{Methods}

We did a prospective audit on follow up patients and their clinic records on the treatment of epilepsy. We selected the first 100 follow up patients, who are diagnosed to have epilepsy, attending the Neurology Clinic of University Medical Unit. All the patients were interviewed by the investigators and the following data were collected; Bio data, type of seizure and type of epilepsy if classified, seizure frequency, possible factors contributing to seizure frequency and details of the treatment. The dose frequency, compliance and side effects were documented. Use of folate supplements in females of reproductive age group was also documented.

Any patient with poor control or any other problem related to epilepsy was discussed with the Consultant Neurologist and remedial measures were taken. Necessary modifications in the management were done at the same time with the Consultant Neurologist's opinion. For the assessment purpose first 100 patients (from March to June 2006) were used.

\section{Results}

\section{Baseline characteristics}

$40 \%$ of the patients were males and $60 \%$ were females. The mean age of the patients is 31.44 years within the range of 10 to 86 years. $77.5 \%$ (31) females were in the child bearing age group and $7.5 \%$ (3) out of them were pregnant at the time of audit.

\section{Current treatment}

Drugs used in the clinic include sodium valporate, carbamazepine, phenytoin sodium, clonazepam, phenobarbitone, topiramate, and clobazam. Folic acid supplements were given in relevant cases. Good seizure control is defined as seizure free period of three years or after starting treatment.

The numbers and percentages of patients who are receiving these antiepileptics is shown in table 1.

Table 1 - The percentages of patients who are receiving antiepileptics

\begin{tabular}{|l|c|}
\hline Drugs & \% of patients \\
\hline Conventional drugs & \\
Sodium valporate & $69 \%$ \\
Carbamazepine & $55 \%$ \\
Phenytoin sodium & $20 \%$ \\
Phenobarbitone & $7 \%$ \\
\hline Other drugs & \\
Clonazepam & $4 \%$ \\
Topiramate & $3 \%$ \\
Clobazam & $5 \%$ \\
Lamotrigine & - \\
Ethosuximide & - \\
\hline
\end{tabular}

Fifty five percent (55\%) of the study population were on monotherapy and out of them $43.63 \%$ (24) had good control. Forty five (45\%) were on polytherapy while $11.11 \%$ (5) from that group had good control. 
Therefore majority of the patients in both groups had poor seizure control. In this matter we have found that there are some other contributory factors for the poor seizure control and the necessary measures were taken to eliminate them.

Eighty eight percent of patients were on conventional drug treatment. Twelve percent patients are on newer antiepileptic drugs in addition to conventional treatment.
Only $31.46 \%$ (28) patients on conventional treatment have good seizure control whereas 9.09\% patients on newer therapy in addition to conventional treatment had good control.

Treatment of the specific seizure types are shown in table 2 .

Table 2 - Usage of drugs in the treatment of the specific seizure types

\begin{tabular}{|c|c|c|c|c|c|c|c|c|c|}
\hline & 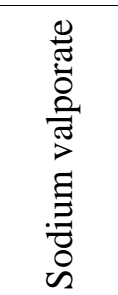 & 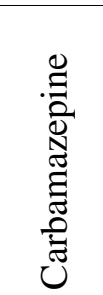 & 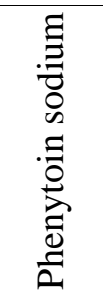 & 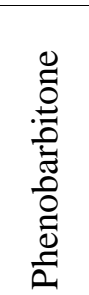 & 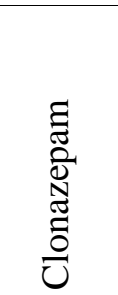 & 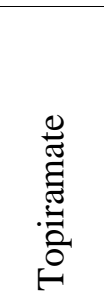 & $\begin{array}{l}\text { E } \\
\text { ָี } \\
0 \\
0 \\
0\end{array}$ & 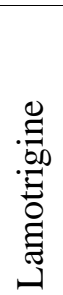 & 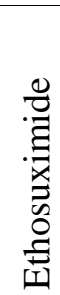 \\
\hline $\begin{array}{l}\text { 1.Simple partial } \\
\text { seizure }\end{array}$ & $\begin{array}{c}1 \\
27 \% \\
(3)\end{array}$ & $\begin{array}{c}1 \\
27 \% \\
(3)\end{array}$ & $\begin{array}{l}18 \% \\
(2)\end{array}$ & $\begin{array}{c}2 \\
9 \% \\
(1)\end{array}$ & & 2 & 2 & 2 & \\
\hline $\begin{array}{l}\text { 2.Complex partial } \\
\text { seizure }\end{array}$ & $\begin{array}{c}1 \\
33 \% \\
(10)\end{array}$ & $\begin{array}{c}1 \\
42.9 \% \\
(13)\end{array}$ & $\begin{array}{c}1 \\
6 \% \\
(2)\end{array}$ & $\begin{array}{c}2 \\
9 \% \\
(3)\end{array}$ & $\begin{array}{c}3.3 \% \\
(1)\end{array}$ & $\begin{array}{c}2 \\
6 \% \\
(2)\end{array}$ & $\begin{array}{c}2 \\
6 \% \\
(2)\end{array}$ & 2 & \\
\hline $\begin{array}{l}\text { 3. Secondarily } \\
\text { generalized } \\
\text { seizure }\end{array}$ & $\begin{array}{c}1 \\
41 \% \\
(10)\end{array}$ & $\begin{array}{l}33 \% \\
(8)\end{array}$ & $\begin{array}{c}20.8 \% \\
(5)\end{array}$ & 2 & $\begin{array}{l}4 \% \\
(1)\end{array}$ & 2 & 2 & 2 & \\
\hline $\begin{array}{l}\text { 4. Generalized tonic } \\
\text { clonic seizures }\end{array}$ & $\begin{array}{c}1 \\
45.9 \% \\
(40)\end{array}$ & $\begin{array}{c}1 \\
31 \% \\
(27)\end{array}$ & $\begin{array}{c}1 \\
14.9 \% \\
(13)\end{array}$ & $\begin{array}{c}2 \\
4.5 \% \\
(4)\end{array}$ & $\begin{array}{l}1.1 \% \\
(1)\end{array}$ & 2 & $\begin{array}{l}2.2 \% \\
(2.2)\end{array}$ & 2 & \\
\hline 5.Absence seizures & $\begin{array}{c}1 \\
42.9 \% \\
\text { (3) }\end{array}$ & $\begin{array}{l}57.1 \% \\
(4)\end{array}$ & & & 2 & & & 2 & 1 \\
\hline $\begin{array}{l}\text { 6. Myoclonic } \\
\text { seizures }\end{array}$ & $\begin{array}{c}1 \\
62.5 \% \\
(5)\end{array}$ & $\begin{array}{l}25 \% \\
(2)\end{array}$ & & 2 & 1 & $\begin{array}{c}12.5 \% \\
\text { (1) }\end{array}$ & & & \\
\hline $\begin{array}{l}\text { 7. Unclassified } \\
\text { seizures }\end{array}$ & $\begin{array}{c}33 \% \\
(2)\end{array}$ & $\begin{array}{c}50 \% \\
(3)\end{array}$ & & & $\begin{array}{l}16.6 \% \\
(1)\end{array}$ & & & & \\
\hline
\end{tabular}

Number shown in right upper corner

1. Indicates the recommended first line therapy

2. Indicates the recommended second line therapy number shown in parentheses are absolute numbers of patients.

Out of the poorly controlled population $11 \%$ received suboptimal doses, $4 \%$ had suboptimal frequency and $46 \%$ had poor compliance with treatment. In most of the seizure types our clinic patients were on the recommended therapy for that seizure type. But there are instances where we had to use the drugs that are available in our clinics due to non availability. The drug levels were done in two patients (carbamezapine) with poor seizure control and they were normal.

Folic acid usage among the females of child bearing age group was $80.64 \%$ and the remaining $19.36 \%$ were advised on the necessity of folic acid and were started on at the same time. 


\section{Conclusions}

In general about $80 \%$ of the patients with epilepsy can be managed with a single drug. The drugs selected for specific seizure type in our clinic seems to be acceptable, but the dose and the compliance need to be improved. The lack of free availability of facilities for drug levels may have contributed for sub optimal results we had seen. Another reason is the fact the more patients with difficult seizure control being concentrated in our clinic. The patient with good control may not be attending the clinic regularly and may be taking drugs locally. On the other hand there may be factors other than the drug related causes for poor control which we have not addressed in this audit. To improve the treatment of epilepsy in clinic setting more attention should be paid to selection of drug and the dose and compliance. A simple leaflet on basic instructions may improve the compliance. Therapeutic drug levels should be available for adjusting the dose in difficult cases. Free availability of newer antiepileptic like topiramate in the hospital may also help in better seizure control in our patients.

\section{References}

1. Keith R, Peter T, Kirti S, Mumtaz A, Graham C, Pippa R, Joanne D, Margaret T. Audit of the care patients with epilepsy in general practice. British Journal of General Practice, 1996; 46: 731-4.

2. Jacoby A, Graham-Jones S, Baker G, Ratoff L, Heyes J, Dewey M, Chadwick D. A general practice records audit of the process of care for people with epilepsy. British Journal of General Practice 1996; 46: 595-9.

3. Goodwin M, Wade D, Luke B, Davies P. A survey of a novel epilepsy clinic. Seizure 2002; 11: 519-22.

4. Classification scheme. International League Against Epilepsy. Revised 1989. 